\title{
ETAPAS DE DIMENSIONAMENTO DE TREM DE POUSOTRICICLO PARA AERONAVES RADIO CONTROLADAS SAE AERODESIGN
}

\section{SIZING STEPS OF TRYCICLE LANDING GEAR FOR SAE AERODESIGN RADIO- CONTROLLED AIRPLANES}

\author{
F. A. B. D. MORAES ${ }^{1 *}$ e C. L. SILVA $^{1}$
}

${ }^{1}$ Universidade Federal de Viçosa, Departamento de Engenharia de Produção e Mecânica, Viçosa, Minas Gerais, Brasil

*Autor correspondente. Universidade Federal de Viçosa, Departamento de Engenharia de Produção e Mecânica, Viçosa, Minas Gerais, Brasil, Phone: +55 31

36126500

Endereço de e-mail: filipeabdalabento@hotmail.br(F.A. B D. Moraes).

\begin{tabular}{l} 
A R T I C L E I N F O \\
\hline Article history: \\
Received 2019-05-18 \\
Accepted 2019-07-24 \\
Available online 2019-08-20 \\
pa lavra - ch h ve \\
Trem de pouso \\
Material compósito \\
Dimensionamento \\
ke yw or $d s$ \\
Landing gear \\
Sizing \\
Composite materials
\end{tabular}

\begin{abstract}
R E S U M O
A competição SAE Brasil AeroDesign, é um evento que ocorre desde 1999 na cidade de São José dos Campos, visando através de uma competição avaliar projetos e construção de aeronaves por alunos de Engenharia de universidades Brasileiras e do Exterior. As aeronaves devem apresentar elevada eficiência estrutural e carregar a máxima carga possível, obedecendo às restrições de projeto da competição. Um dos componentes estruturais das aeronaves é o Trem de Pouso, devendo apresentar propriedades como rigidez e robustez, mas também boa relação entre peso e resistência. A equipe "Skywards UFVoa" da Universidade Federal de Viçosa visa aprofundar seus esforços no dimensionamento em materiais compósitos deste e de outros componentes, bem como métodos de fabricação mais eficazes. Este trabalho demonstra o dimensionamento de um Trem de Pouso que atenda as demandas do projeto da competição de 2018.
\end{abstract}

A B S T R A C T

The SAE Brazil AeroDesign competition is an event that occurs since 1999 in the city of São José dos Campos, aiming through a competition to evaluate the project and construction of aircrafts by Brazilian and foreigner engineering students. The airplanes must show high structural efficiency and carry as much load as possible, following the competition project restrictions. The landing gear is one of the structural components that needs to show properties like stiffness and sturdiness as well as a good relation between weight and strength. The "skywards UFVoa" team from the Federal University of Viçosa aim to deepen their efforts on the sizing of this and others structural component in composite materials and more efficient manufacturing methods. This article shows the sizing of a landing gear that match the project demands of the 2018's edition of the SAE AeroDesign competition. 


\section{INTRODUÇÃO}

Um avião é definido como uma aeronave de asa fixa mais pesada que o ar, movida por propulsão mecânica, que é mantido em condição de vôo devido a reação dinâmica do ar que escoa através de suas asas. São projetados para uma grande variedade de propostas, porem todos possuem os mesmos componentes principais Rodrigues et al. (2010). Ao longo dos anos o avião vem se tornando um meio de transporte bem popular devido a velocidade de transporte e por ser também muito seguro, isso devido a esforços de engenheiros e estudiosos que sempre buscaram e ainda buscam entender os fenômenos que ocorrem com a aeronave e com sua estrutura durante vôo.

O interesse pela área aeronáutica é tão grande que muitos entusiastas buscam aprender mais sobre aeronaves através do aeromodelismo, muitas vezes fazendo deste seu hobby. Já estudantes de curso superior como futuros profissionais de engenharia que desejam atuar no mercado aeronáutico, reúnemse no aerodesign. $\mathrm{O}$ projeto de aerodesign diferentemente de um projeto de aeromodelo, é uma aeronave também em escala reduzida, porem que busca completar missões de vôo e carregar carga, apresenta componentes com uma necessidade de resistência estrutural muito maior e é projetado para situações mais críticas de vôo, atendendo também as restrições de projeto apresentadas pela comissão da competição que normalmente estes estudantes estão escritos. No Brasil estudantes de universidades de todo país participam da competição SAE Brasil Aerodesign.

Historicamente na competição SAE Brasil Aerodesign, o Trem de Pouso juntamente com fuselagem e longarina é um dos componentes que frequentemente apresenta falha no momento do vôo, pois condições adversas na competição podem fazer com que estes componentes sejam fortemente solicitados. Sendo assim, tais componentes necessitam de cuidado especial na hora de seu dimensionamento e construção para garantir a equipe uma maior competitividade na competição. Este trabalho tem como objetivo demonstrar uma das diversas maneiras de dimensionar e fabricar um trem de pouso na configuração triciclo para um aeromodelo desenvolvido para a competição SAE Brasil Aerodesign.

\section{TREM DE POUSO}

O trem de pouso é um componente estrutural que tem como objetivo dissipar a energia proveniente da descida vertical da aeronave em contato com o solo, suportar o peso estático da mesma e ainda ser projetado para resistir à operação de rolagem da aeronave na pista de pouso Niu et al. (1995). Usualmente o trem de pouso pode ser dividido em trem principal, trem de nariz ou trem de cauda.

O trem de pouso apresenta diversos tipos de configurações possíveis; Raymer et al. (1999) consideram a existência de 6 tipos de configurações, porém, assim como Rodrigues et al. (2011), ambos salientam que as mais utilizadas são a triciclo e a convencional. Estas diferem entre si pois para o caso triciclo podemos dividir o componente em trem principal que se localiza atrás do centro de gravidade da aeronave e o trem de nariz que se localiza a frente do mesmo e mais próximo ao nariz da aeronave, diferentemente para o caso convencional onde este componente é divido em trem principal que se localiza a frente do centro de gravidade e trem de cauda que se localiza atrás deste e mais próximo a empenagem.

Atualmente a configuração triciclo é amplamente utilizada pois apresenta algumas vantagens em relação a convencional. Segundo Pazmany et al. (1963), algumas destas vantagens são:

- A configuração triciclo permite a aeronave estar mais nivelada com o solo, permitindo uma entrada e saída mais confortável do cockpit;

- Permite uma melhor visibilidade da pista durante as corridas em solo (decolagem, pouso ou taxiamento);

- Contribui para uma maior estabilidade e manobrabilidade em solo;

- Resulta em um menor ângulo de incidência da asa com o solo, permitindo uma decolagem mais rápida e com menor comprimento de pista;

- Reduz as possibilidades de impacto da cauda da aeronave com o solo.

\section{METODOLOGIA}

No desenvolvimento deste trabalho utilizou-se a bibliografia Pazmany et al. (1963) e a norma FAR PART 23 para obtenção de alguns ângulos característicos e realização de ensaio seguindo uma normatização amplamente aceita. A sequência de execução dos passos foi definida pelos membros do setor de Estruturas da equipe "Skywards UFVoa".

Para se definir a geometria de um trem de pouso deve-se primeiro escolher qual será sua configuração, podendo ser triciclo ou convencional, pois tal configuração indica de maneira inicial a posição do trem de pouso principal e do trem de nariz. Após esta etapa é necessário escolher o diâmetro das rodas do seu conjunto, para que não ocorra de alguma parte da geometria do trem principal encoste no solo e impossibilite as rodas de fazerem o mesmo.

A geometria do trem principal deve ser pensada em conjunto com a sua forma de fixação a fuselagem. Para isso necessita-se que a fuselagem esteja pronta ou ao menos bem definida, para que não seja feita uma geometria impossível de conectar a fuselagem ou que se faça de maneira demasiadamente trabalhosa. Em seguida deve-se determinar as dimensões do trem principal para que este possa então ser construído e, por fim, a realização de drop test para validação da geometria.

\section{RESULTADOS E DISCUSSÃO}

\subsection{Dimensionamento Das Rodas}

Considerando o projeto como sendo um avião de transporte de carga com $\mathrm{Pt}=11,9$ [kg], Wd como carga em uma roda e utilizando a Equação 1, tem-se que o diâmetro das rodas deve ser de $60 \mathrm{~mm}$ e a largura de $7 \mathrm{~mm}$, fabricadas em liga de alumínio conforme exemplificado na Tabela 1 . Visto que as aeronaves de aerodesign não são muito pesadas e nem muito altas, tal tamanho de roda se mostra satisfatório.

$W d=K \times(P t \times n)^{G}$ 
Tabela 1 - Dimensionamento das rodas do trem principal. Adaptado de Raimer (1989).

\begin{tabular}{l|c|c|c|c} 
& \multicolumn{2}{c}{ Diâmetro/ polegada } & Largura/ polegada \\
& $\mathrm{K}$ & $\mathrm{G}$ & $\mathrm{K}$ & $\mathrm{G}$ \\
\hline $\begin{array}{l}\text { Aviação } \\
\text { Geral }\end{array}$ & 1,51 & 0,349 & 0,715 & 0,312 \\
\hline Comercial & 2,69 & 0,251 & 1,17 & 0,216 \\
\hline Transporte & 1,63 & 0,315 & 0,1043 & 0,48 \\
\hline Jatos & 1,59 & 0,302 & 0,098 & 0,467 \\
\hline
\end{tabular}

\subsection{Fixação Em Fuselagem}

A fuselagem do presente trabalho foi do tipo treliçada, conforme Figura 1(a). Para a fixação do trem principal foi idealizada uma peça composta por dois retângulos que apresentam um rasgo em uma de suas extremidades para o encaixe do mesmo, mantendo o resto dos retângulos todo preenchido até a outra extremidade, a qual encosta na placa presente na parte traseira da fuselagem.

A fim de fixar o trem de pouso e torná-lo cambiável entre aeronaves, foi adicionada uma placa composta por um "sanduíche" de madeira balsa e fibra de carbono entre os retângulos - Figura 1(b). A fixação do conjunto de encaixe foi feita amarrando o mesmo a fuselagem utilizando fios de fibra de carbono juntamente com resina epóxi, o que dificulta o cálculo de resistência da fixação, já que as fibras estão dispostas em direções aleatórias. A montagem do conjunto pode ser observada na Figura 2.
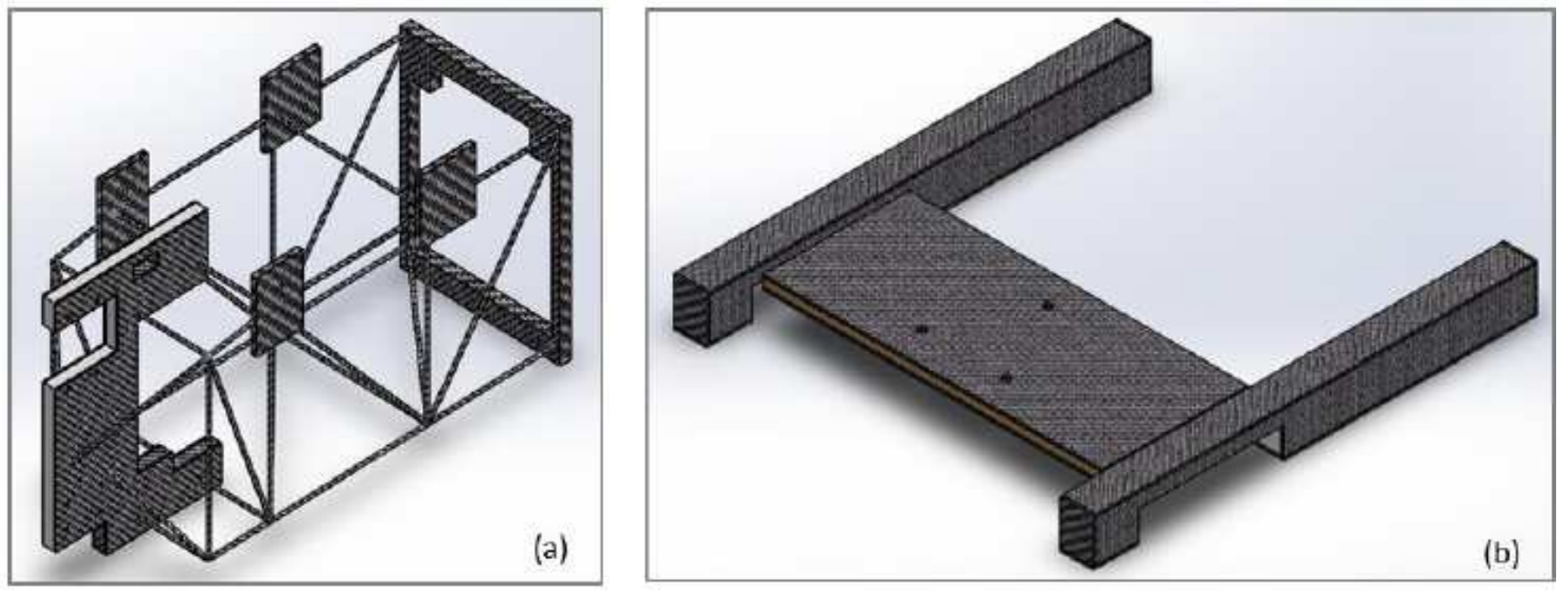

Figura 1 - (a) vista isométrica fuselage; (b) vista isométrica do encaixe trem de pouso.

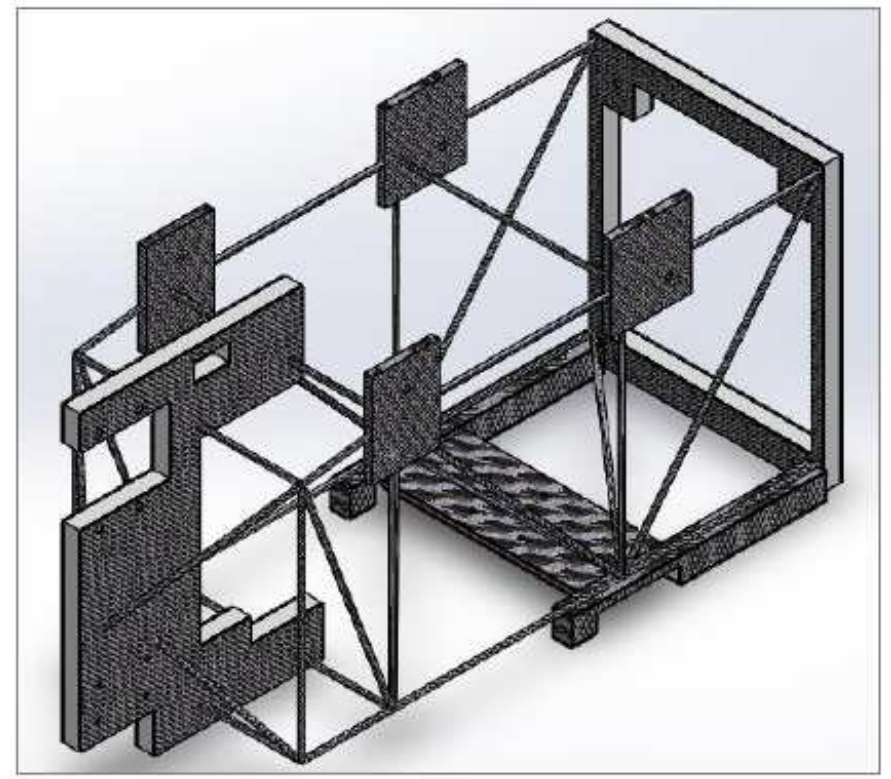

Figura 2 - Montagem do conjunto.

\subsection{Geometria e Fabricação Do Trem de Pouso}

O trem de pouso principal foi pensado para ser no modelo que se assemelha a uma viga engastada. Tal semelhança foi alcançada utilizando uma placa de sanduiche de espuma de PVC Divinycell $\mathrm{H} 45^{\circledR}$ com fibra de carbono como apoio e um eixo como elemento engastado. Na Tabela 2 são descritos todos os materiais utilizados para a fabricação.
Tabela 2 - Materiais e descrição.

\begin{tabular}{l|c}
\multicolumn{1}{c|}{ Materiais } & Descrição \\
\hline $\begin{array}{l}\text { Tecido fibra de carbono } \\
\text { trama plana }\end{array}$ & 2 camadas por face \\
\hline $\begin{array}{l}\text { Tubo maciço de fibra de } \\
\text { carbono }\end{array}$ & Diâmetro $8 \mathrm{~mm}$ \\
\hline Parafuso Allen aço liga & $2 \mathrm{M} 5$ \\
\hline $\begin{array}{l}\text { Espuma de PVC Divinycell } \\
\text { H45 }\end{array}$ & 1 Placa \\
\hline Resina epóxi ampreg & Proporções do fabricante \\
\hline
\end{tabular}

O processo de fabricação teve início na preparação de uma placa de sanduiche de espuma PVC divinycell $\mathrm{H} 45^{\circledR}$ com duas camadas de fibra de carbono em cada face como pode ser observado pela Figura 3. Em seguida cortou-se do tubo de fibra de carbono um comprimento igual ao da placa sanduiche. A fim de melhorar a área de contato entre os componentes, foi feito um pequeno aplainamento no eixo, visto que o mesmo seria unido a placa utilizando resina, fez-se necessário tal aumento de superfície de contato para garantir uma maior aderência do eixo a placa. Na Figura 3 (b) é possível observar o aplainamento que se encontra destacado. O planejamento inicial era unir o eixo com o rolamento das rodas através de um ajuste por interferência, porem devido ao baixo coeficiente de atrito proporcionado pelo carbono do eixo esta não era mais uma alternativa viável. Encontrou-se como solução a adição de parafusos nas pontas do eixo, sendo necessário aumentar a superfície de contato tanto no eixo quanto nos parafusos, sendo 
tais superfícies obtidas com o uso de lima e esmeril respectivamente. É possível observar o resultado final do eixo

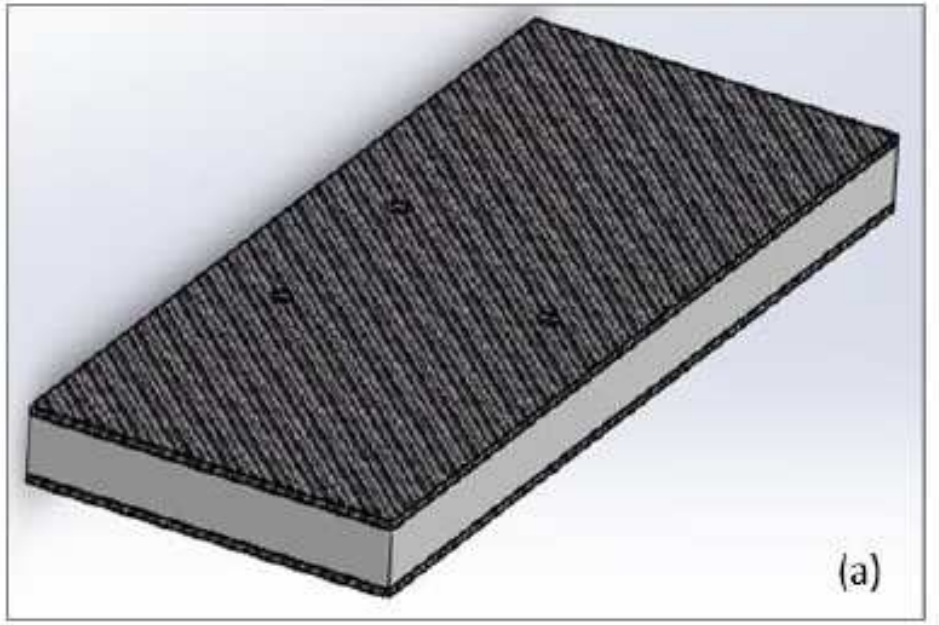

na Figura 3(c).

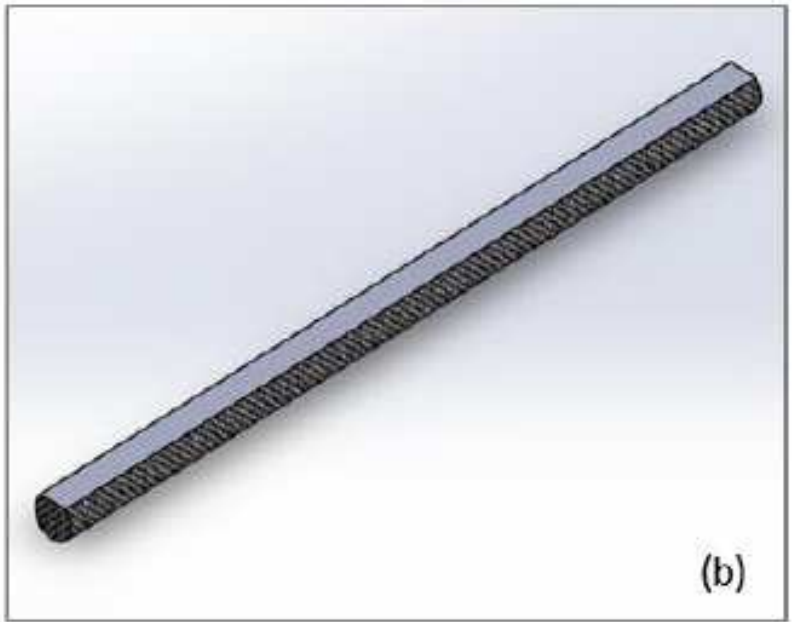

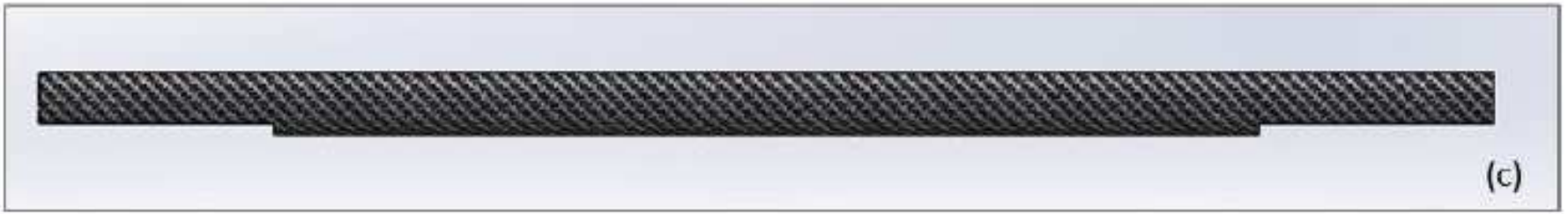

Figura 3 - (a) placa sanduiche; (b) eixo com superfície planificada destacada; (c) aumento de superfície de contato para parafusos.

Os parafusos escolhidos foram esmerilhados até o início de suas roscas e fixados ao eixo sendo amarrados com fios de fibra de carbono e resina depositada sobre os fios, já o eixo teve resina aplicada diretamente na superfície de contato e em seguida foi colocado em contato com a placa. A fim de dar uma maior rigidez ao sistema e garantir que o eixo não se separasse da placa, cortou-se um retângulo de fibra de carbono com as dimensões exatas para encaixar entre os parafusos e que também desse três voltas ao redor da placa. Após aplicar resina na fibra de carbono, o conjunto em questão foi colocado em um saco a vácuo para melhorar a aderência no conjunto placa/eixo durante o processo de cura da resina e para retirar excesso de resina. $\mathrm{O}$ resultado final em vista superior e em vista inferior na Figura 5.

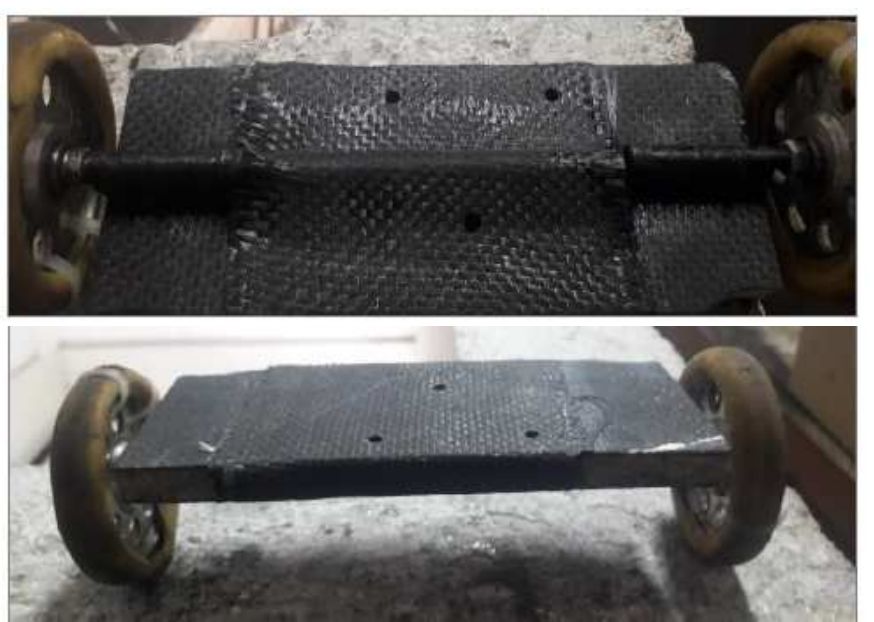

Figura 4 - Resultado final vista inferior e vista superior.

\subsection{Dimensões Do Trem De Pouso}

Para se obter as dimensões do trem principal, algumas distâncias e as coordenadas do centro de gravidade da aeronave devem ser consideradas. A Figura 5 exemplifica a obtenção de tais distâncias. Overturning é o rolamento lateral da aeronave, ocasionado por ventos laterais durante o pouso. Segundo Torenbeek et al. (1982) o ângulo de overturning pode ser facilmente obtido através de uma simples regra de polegar, não devendo exceder $60^{\circ}$, porém, experimentalmente foi estabelecido como limite de segurança aceitável um ângulo entre 55 e $57^{\circ}$, para evitar o rolamento lateral da aeronave.

Segundo Roskam et al. (1958) e Pazmany et al. (1963), quando observado em vista lateral, o ângulo de toque entre as rodas do trem principal e o solo deve ser de $15^{\circ}$ em relação ao centro de gravidade, obtendo-se assim a distância entre centro de gravidade e ponto onde as rodas tocam o solo. A Figura 6 demonstra a obtenção da distância do ponto de toque ao centro de gravidade em função da distância $\mathrm{E}=14,3$ [cm] e do ângulo de $15^{\circ}$ utilizando a Equação 2.

$\operatorname{tg} 15^{\circ}=\frac{x}{14,3} \rightarrow x=3,83 \mathrm{~cm}$

Logo as rodas do trem principal tocarão o solo a $3,83 \mathrm{~cm}$ do centro de gravidade da aeronave. A Figura 7 exemplifica a posição do ângulo de overturning, ao substituir E, A e B nesta figura, chega-se a um valor de track mínimo de $\mathrm{T}=7,66 \mathrm{~cm}$, porém, como a dimensão da fuselagem é maior que T mínimo, optou-se então por utilizar T=16,6 cm. 

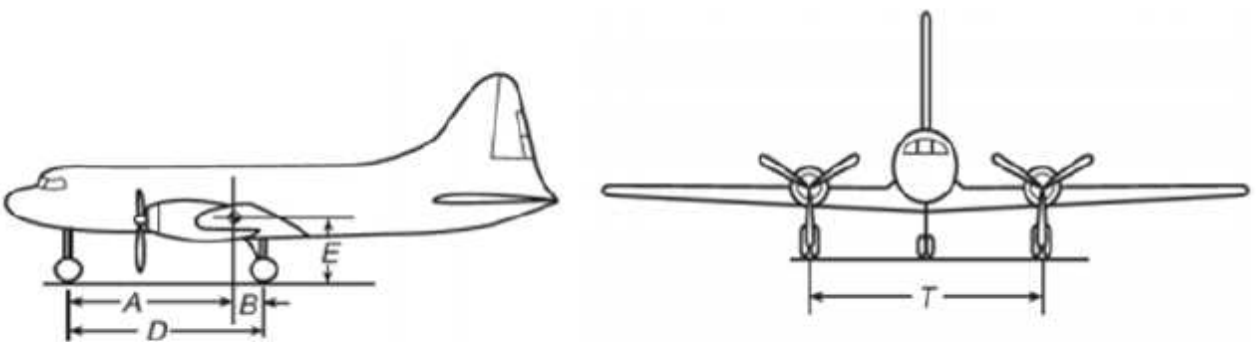

$$
\begin{aligned}
& A=\text { distância entre } \circ \mathrm{cg} \text { da aeronave e o trem de pouso frontal }[\mathrm{m}] \\
& B=\text { distância do } \mathrm{cg} \text { da aeronave e o trem de pouso principal }[\mathrm{m}] \\
& D=\text { distância total entre eixos }[\mathrm{m}] \\
& \mathrm{E}=\text { altura do cg em relação ao solo }\left(\mathrm{h}_{\mathrm{cg}}\right)[\mathrm{m}] \\
& T=\text { Track (distância entre rodas do trem de pouso principal da aeronave) }
\end{aligned}
$$

Figura 5 - Distâncias para dimensionamento de trem de pouso.

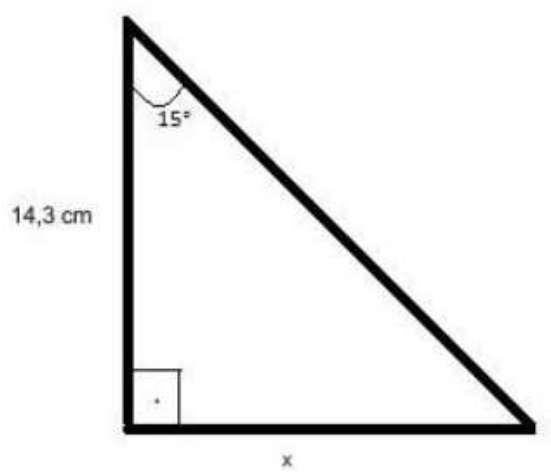

Figura 6 - Demonstração da distância do ponto de toque ao cg.

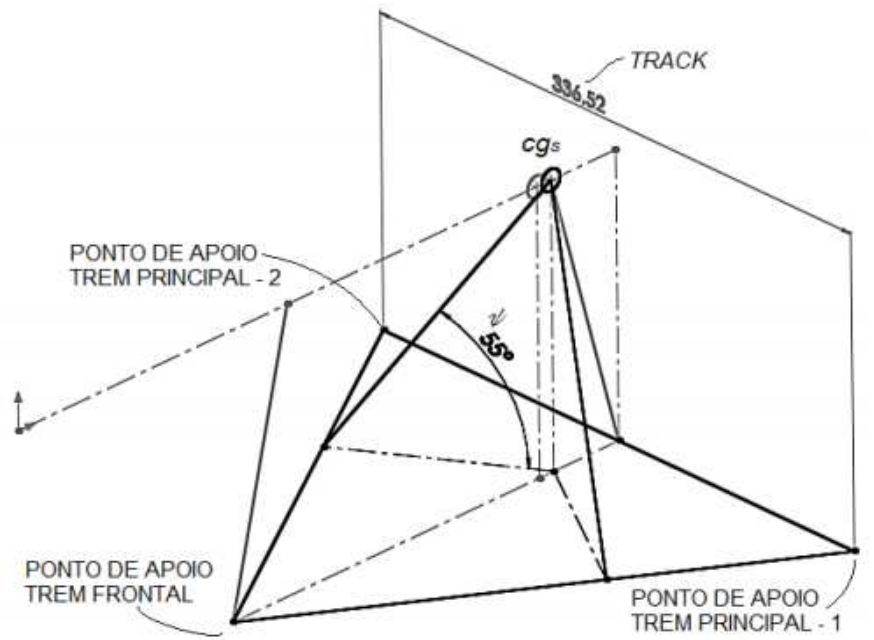

Figura 7 - Posição do ângulo de overturning .

\subsection{Validação por Drop Test}

A competição SAE Brasil Aerodesign exige relatórios de projeto de todos os setores das equipes competidoras. No caso do setor de estruturas, um teste muito importante para validação do projeto é o drop test de trem de pouso. Tal teste consiste em colocar carga sobre o componente e abandona-lo de certa altura, visando simular uma situação crítica de pouso, para analisar o quanto de carga o trem de pouso será capaz de suportar. Este teste foi executado seguindo a norma FAR PART 23 para a determinação da altura que o componente deve ser abandonado para sua validação. A Equação 3 demonstra como esta altura é obtida.

$h($ polegadas $)=3.6 \times \frac{W}{S} \times \frac{1}{2}$

onde $\mathrm{W}=$ MTOW (peso da aeronave somado a carga carregada) $=11,9[\mathrm{~kg}]=78,7050[\mathrm{lbs}]$ e $\mathrm{S}=$ Área da asa $=0,8568\left[\mathrm{~m}^{2}\right]=$ 9,22 [ft²], obteve-se um h de 15,6 [in] $(39,62$ [cm]), para fins de praticidade adotou-se $h=40[\mathrm{~cm}]$. A norma também estabelece que a altura mínima de soltura deve ser de 9,2 [in] (23 [cm]) e a máxima de 18,7 [in] (48 [cm]). A fim de quantificar as forças que o componente estará sujeito, faz-se necessário o uso de um acelerômetro. Utilizando a segunda Lei de Newton e os dados obtidos do sensor é possível verificar nas Figuras 8 e 9 as cargas em Newton que agem no trem principal.

\section{CONCLUSÕES}

Este trabalho apresentou todo o processo de projeto e construção de um trem de pouso que foi realizado pela equipe Skywards UFVoa da Universidade Federal de Viçosa para o projeto de 2018 que participou da $20^{\circ}$ Competição SAE Brasil AeroDesign. Como os resultados alcançados conclui-se que:

- A fixação do trem de pouso em uma aeronave de fuselagem treliçada deve ser projetada juntamente com a geometria do trem principal, pois projetar conexões para fixação neste tipo de fuselagem se dá de maneira mais trabalhosa, logo a fixação já deve ser idealizada para acomodar perfeitamente a geometria definida para o trem de pouso;

- A utilização de um eixo de carbono com o comprimento exato da placa sanduiche elimina a ocorrência de um braço de alavanca que geraria um momento sobre o eixo, logo o mesmo seria mais solicitado. Mesmo com a adição de parafusos na extremidade, o braço de alavanca gerado pela utilização de porcas auto-travante para fixação das rodas é mínimo, pois a rosca dos parafusos começa justamente na extremidade do eixo; 
- Tal geometria de trem principal mostrou-se de fácil fabricação, pois todos seus componentes são de geometria simples. A maior parte do tempo demandado

$5 \mathrm{~kg}$

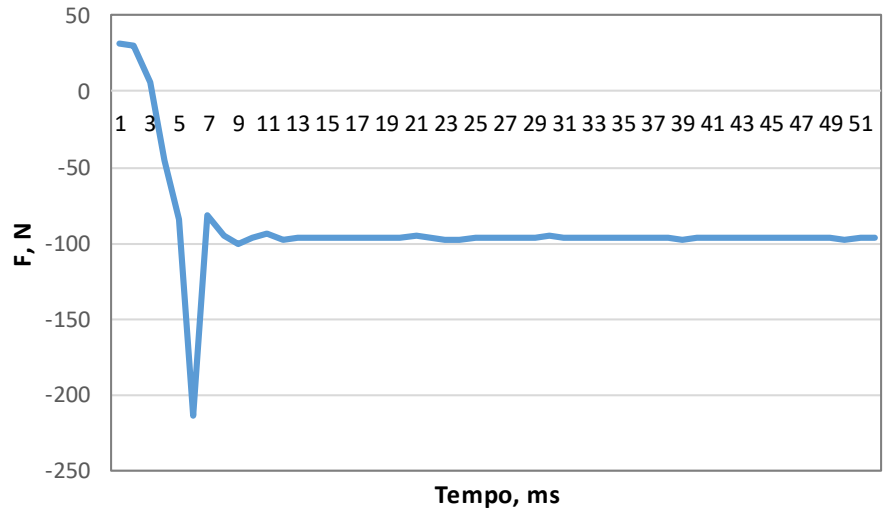

para a finalização da fabricação se deve ao tempo de cura da resina, utilizada em vários componentes e etapas do processo de fabricação.

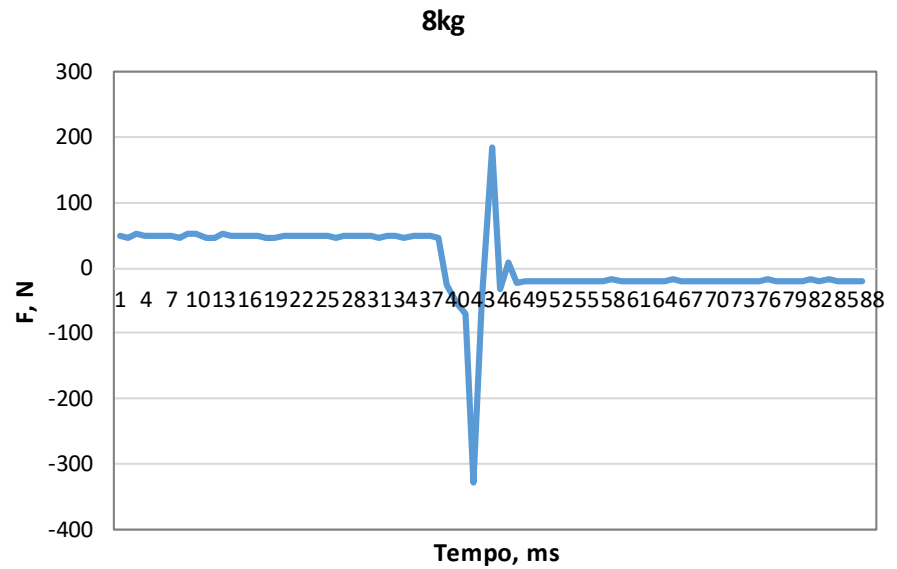

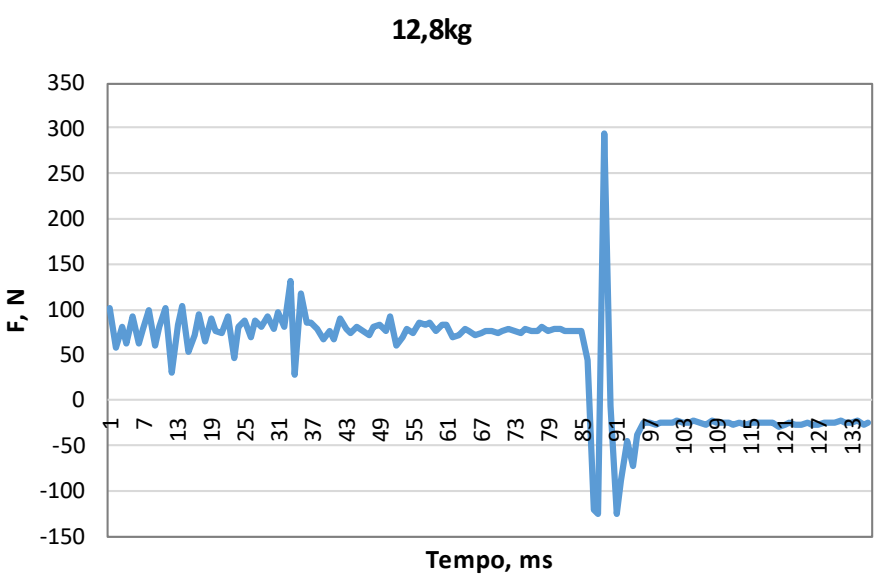

Figura 8 - Carga em trem de pouso drop test $5 \mathrm{~kg}$; carga em trem de pouso drop test $8 \mathrm{~kg}$; carga em trem de pouso drop test $12,8 \mathrm{~kg}$.

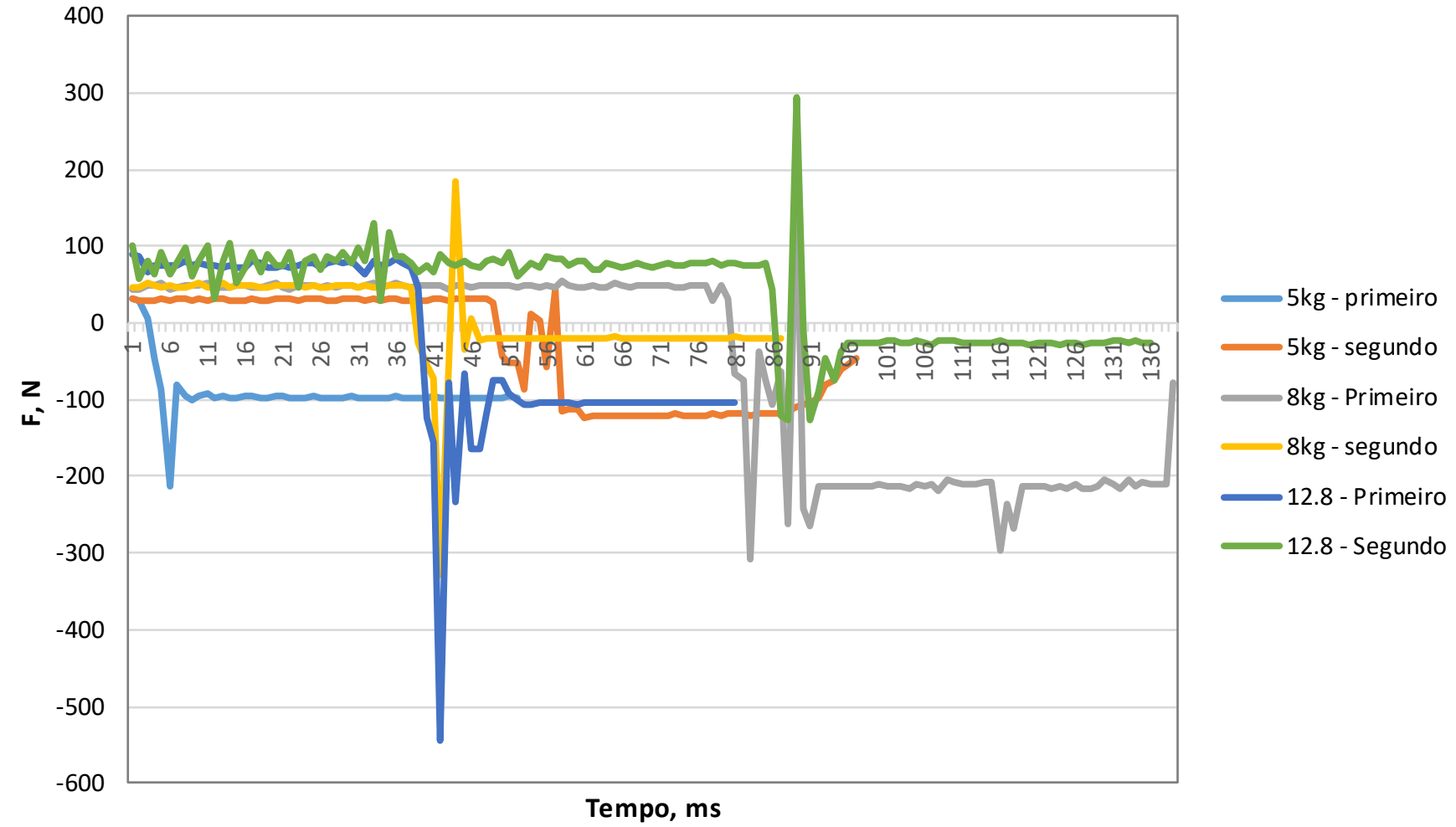

Figura 9 - Resultados drop test. 


\section{R E F E R E N C I A S}

FÉLIX, P. H. W. - Caracterização mecânica de matérias compostos. Minas gerais: UFV, 2013. 28p.

FAR - Part 23 Airworthiness standards: normal, utility, acrobatic and commuter.

ARAUJO, E. Modelando Materiais Compostos Laminados com o Ansys V15, Disponível em: http://library.esss.com.br/analise_materiais_compositos _tk_, acessado em: 15/11/2018.

ISCOLD, P. - Introdução as cargas nas Aeronaves - EE UFMG, Centro de Estudos Aeronáuticos, 2011.

NIU, M. C-Y. Airframe Stress Analysis and Sizing. Second
Edition - Hong Kong Conmilit Press LTD, 1999.

NIU, M. C-Y. Airframe Structural Design. Second Printing, Hong Kong Conmilit Press LTD, 1989.

PAZMANY, L. Light Airplane Design - San Diego, California, $3^{\text {a }}$ Edição, 1963.

RAYMER, D. P. Aircraft Design: A Conceptual Approach. Third Edition AIAA - American Institute of Aeronautics and Astronautics, 1999.

RODRIGUES, L. E. M. J. Fundamentos da Engenharia Aeronáutica - Aplicações ao Projeto SAE-AeroDesign. Volume Único. 1. Ed. rev. - Instituto Federal de Educação, Ciência e Tecnologia de São Paulo, São Paulo, 2011. 